\title{
REMEDIASI MISKONSEPSI PESERTA DIDIK PADA MATERI OPTIK DENGAN TEKNIK CRI MODIFIKASI MELALUI MODEL LEARNING CYCLE 5E
}

\author{
Haeroni*, Susilawati, Satutik Rahayu \\ Program Studi Pendidikan Fisika, Universitas Mataram \\ *Email: haeroni59@ymail.com
}

DOI: http://dx.doi.org/10.29303/jpft.v5i1.835

\begin{abstract}
This research aimed to find out the level of misconceptions and the effect of 5e learning cycle model. This research was a pre-experimental with pre-test and post-test design. The research population was all of the eleven grade students of Senior High School 1 Mataram consisted of 8 classes. Sampling was done by cluster random sampling technique and obtained students of class XI MIPA 5. Students' misconceptions have been identified by modification of Certainty of Response Index technique and remediated with 5e learning cycle model. The result of data analysis showed that students experience misconceptions with the various level that was high, medium, and low. The misconception of students before remediation was $44 \%$ in the concept of reflection and $34 \%$ in the concept of refraction, meanwhile, after remediation, the misconceptions on the concept of reflection was $6 \%$ and the concept of refraction was $9 \%$. As a result, 5e learning cycle model could decrease the level of misconception. It showed that 5e learning cycle model was effective to decrease the level of misconception. From the paired sample $t$-test, it was found that $t_{\text {count }}=8,042$ and $t_{\text {table }}=2,045$, because of $t_{\text {count }}>t_{\text {table }}$ there was an effect of 5e learning cycle model on a misconception.
\end{abstract}

Keywords: Misconception, Certainty of Response Index, Optic, Remediation, 5e Learning Cycle

PENDAHULUAN

Fisika merupakan salah satu bagian dari Ilmu Pengetahuan Alam (IPA) yang berkembang dari pengamatan gejala-gejala alam dan interaksi yang terjadi di dalamnya. Tujuan pembelajaran fisika yang tertuang di dalam kerangka Kurikulum 2013 ialah menguasai konsep dan prinsip serta mempunyai keterampilan mengembangkan pengetahuan dan sikap percaya diri sebagai bekal untuk melanjutkan pendidikan pada jenjang yang lebih tinggi serta mengembangkan ilmu pengetahuan dan teknologi.

Berdasarkan tujuan pembelajaran tersebut maka penyelenggaraan mata pelajaran fisika di tingkat SMA/MA harus menjadi wahana atau sarana untuk melatih para peserta didik agar dapat menguasai pengetahuan, konsep, dan prinsip fisika. Taufik et al. (2010), melaporkan hasil identifikasi konsepsi mahasiswa yang menunjukkan tingginya kesalahan konsep yang dialami oleh mahasiswa calon guru fisika semester 6 , dan letak kesalahannya tidak pada perhitungan matematika saja namun juga mahasiswa mengalami miskonsepsi berkaitan dengan konsep gaya dengan tingkatan yang berbeda-beda. Suparno (2013) menyatakan bahwa miskonsepsi menjadi salah satu penyebab rendahnya hasil belajar peserta didik. Akan tetapi fakta yang ditemukan di lapangan adalah hasil belajar yang tinggi tidak menjamin peserta didik menguasai konsep seluruhnya dengan benar.

Miskonsepsi fisika dapat dinyatakan sebagai konsep fisika siswa yang tidak cocok dengan konsep fisikawan yang disederhanakan, hanya dapat diterima dalam kasus-kasus tertentu dan tidak berlaku untuk kasus-kasus lainnya, tidak dapat digeneralisasi dan tidak menunjukkan hubungan antar konsep-konsep fisika (Pebriyanti et al. 2015). Hakim (2012) menyatakan bahwa salah satu indikator terjadinya miskonsepsi adalah jawaban yang diberikan peserta didik benar akan tetapi peserta didik tidak mampu menjelaskan alasan yang tepat dalam menjawab dan sertai 
keyakinan yang tinggi akan kebenaran jawaban yang disampaikan.

Kegiatan belajar mengajar peserta didik pada dasarnya telah membawa pengetahuan awal yang didapatkan dari jenjang pendidikan sebelumnya. Pengetahuan awal ini dikenal dengan istilah prakonsepsi. Guru sebaiknya perlu mengetahui prakonsepsi siswa sebelum memulai pembelajaran serta memberikan penekanan pada konsep yang benar untuk meminimalisasi terjadinya miskonsepsi pada siswa (Lestari, et al. 2015). Prakonsepsi yang dibawa oleh peserta didik ada yang berupa konsep ilmiah ada pula yang merupakan kesalahan konsep. Kesalahan konsep menunjuk pada miskonsepsi. Suparno (2013) menyatakan miskonsepsi adalah suatu konsep yang tidak sesuai dengan konsep yang diakui oleh para ahli. Menurut Irawan et al. (2012) miskonsepsi merupakan pertentangan atau ketidakcocokan konsep yang dipahami seseorang dengan konsep yang dipakai oleh para pakar ilmu yang bersangkutan, sedangkan Taufiq (2012) menyatakan bahwa miskonsepsi adalah konsep yang dipercaya orang walaupun secara objektif salah.

Miskonsepsi yang dialami peserta didik menjadi masalah utama dalam dunia pendidikan saat ini. Adanya miskonsepsi pada peserta didik dapat menyebabkan terjadinya kesulitan dalam memahami konsep-konsep fisika selanjutnya. Miskonsepsi siswa juga akan menghambat proses penerimaan pengetahuan baru yang berusaha dikonstruk melalui pembelajaran di kelas sehingga akan menghalangi siswa dalam proses belajar (Silung, et al. 2016).

Berdasarkan penelitian oleh Lestari, et al. (2015) terdapat miskonsepsi peseta didik kelas X SMKN 4 Mataram pada seluruh konsep kalor serta penelitian oleh Silung, et al. (2016) yang berhasil mendiagnosa adanya miskonsepsi pada konsep suhu dan kalor menggunakan Three Tier Test. Oleh karena itu remediasi miskonsepsi terhadap peserta didik perlu dilakukan. Remediasi adalah salah satu program pengajaran yang bersifat spesifik untuk membenahi atau memperbaiki masalah belajar. Langkah pertama yang harus dilakukan adalah mengidentifikasi miskonsepsi. Salah satu alternatif yang dapat digunakan untuk mengidentifikasi miskonsepsi adalah teknik Certainly of Response Index (CRI).

CRI merupakan ukuran tingkat kepercayaan responden dalam menjawab soal yang diberikan (Hasan, et al. 1999). Teknik ini menggunakan soal tes pilihan ganda disertai dengan indeks keyakinan dan alasan untuk setiap jawaban yang diberikan, berfungsi untuk mengidentifikasi peserta didik yang tahu konsep, miskonsepsi, dan tidak tahu konsep. Ketentuan untuk membedakan antara tahu konsep, miskonsepsi dan tidak tahu konsep menggunakan teknik CRI telah di modifikasi oleh Hakim, et al. (2012). Modifikasinya adalah dengan menambahkan alasan untuk setiap jawaban yang diberikan peserta didik, sehingga ketika peserta didik memilih jawaban yang benar dan alasannya benar meskipun peserta didik tidak yakin dengan jawaban yang tepat dapat dikategorikan memahami konsep. Berdasarkan Tabel 1 dapat diperoleh informasi bahwa terdapat tiga indikator terjadinya miskonsepsi yaitu (1) apabila jawaban benar alasan salah dan CRI tinggi, (2) apabila jawaban salah alasan benar dan CRI tinggi, dan (3) apabila jawaban salah alasan salah CRI tinggi. 
Tabel 1. Kriteria CRI Modifikasi

\begin{tabular}{|c|c|c|c|}
\hline Jawaban & Alasan & Nilai CRI & Deskripsi \\
\hline Benar & Benar & $>2,5$ & Memahami konsep dengan baik \\
\hline Benar & Benar & $<2,5$ & $\begin{array}{l}\text { Memahami konsep tetapi tidak } \\
\text { percaya diri dengan jawaban yang } \\
\text { diberikan }\end{array}$ \\
\hline Benar & Salah & $>2,5$ & Miskonsepsi \\
\hline Benar & Salah & $<2,5$ & Tidak tahu konsep \\
\hline Salah & Benar & $>2,5$ & Miskonsepsi \\
\hline Salah & Benar & $<2,5$ & Tidak tahu konsep \\
\hline Salah & Salah & $>2,5$ & Miskonsepsi \\
\hline Salah & Salah & $<2,5$ & Tidak tahu konsep \\
\hline
\end{tabular}

(Sumber: Hakim, et al. 2012)

Shofiyah (2016) dalam jurnalnya menyatakan bahwa miskonsepsi dapat diubah melalui pemberian pertanyaan, konflik kognitif, dan eksperimen untuk menguji hipotesis. Model siklus belajar (Learning Cycle) 5e dapat mengakomodasi keseluruhan kegiatan yang diharapkan dapat meremediasi miskonsepsi. Model pembelajran learning cycle merupakan model pembelajaran yang berpusat pada peserta didik (student centered). Model siklus belajar (learning cycle) pertama kali dikembangkan oleh Robert Karplus pada tahun 1960 dalam program the Science
Curriculum Improvement Study (SCIS). Siklus belajar menurut program ini terdiri dari tiga fase yaitu: discovery, concept invention, dan concept application. Pada tahun 1989, model siklus belajar dikembangkan menjadi model $5 \mathrm{e}$ oleh the Biological Sciences Curriculum Study (BSCS) yang terdiri dari 5 fase yaitu fase engagement, fase exploration, fase explanation, fase elaboration, dan fase evaluation. Berikut disajikan fase-fase pembelajaran dengan model learning cycle $5 e$ pada Tabel 2 yaitu sebagai berikut:

Tabel 2 Fase Model Pembelajaran Learning Cycle $5 e$

\begin{tabular}{ll}
\hline \multicolumn{1}{c}{ Fase } & \multicolumn{1}{c}{ Aktivitas Peserta didik } \\
\hline Engage & $\begin{array}{l}\text { Mengajukan pertanyaan tentang benda, mahkluk hidup, atau peristiwa } \\
\text { dikehidupan sehari-hari. }\end{array}$ \\
Explore & $\begin{array}{l}\text { Merencanakan dan melakukan penelitian sederhana untuk } \\
\text { mengumpulkan data yang relevan. }\end{array}$ \\
Explain & $\begin{array}{l}\text { Menggunakan data dan pengetahuan ilmiah untuk menjelaskan } \\
\text { pemahamannya. }\end{array}$ \\
Elaborate & $\begin{array}{l}\text { Mengembangkan strategi, konsep, prinsip, dan pemahamannya menuju } \\
\text { masalah dan pertanyaan yang baru. }\end{array}$ \\
& $\begin{array}{l}\text { Mendemonstrasikan pengetahuan, pemahaman, dan keterampilannya } \\
\text { menggunakan strategi inkuiri melalui penilaian formatif formal maupun }\end{array}$ \\
& informal. \\
\hline & (Sumber: Adaptasi dari Bass dan Baybee dalam Hikmawati, 2015)
\end{tabular}

\section{METODE PENELITIAN}

Penelitian yang digunakan adalah penelitian jenis pre experimental dengan desain one group pretest-posttest. Menurut Arikunto (2014) jenis penelitian ini seringkali dipandang sebagai eksperimen yang tidak sebenarnya karena eksperimen jenis ini belum memenuhi persyaratan seperti cara eksperimen yang dilakukan ilmiah mengikuti peraturan-peraturan tertentu. Penelitian ini melibatkan variabel bebas yaitu model pembelajaran learning cycle 5e; variabel terikat yaitu data miskonsepsi; dan variabel control yaitu guru, materi, tujuan pembelajaran dan instrumen penelitian. Berikut disajikan design penelitian seperti yang dikutip dalam Sugiono (2016). 
Tabel 3. Desain Penelitian

\begin{tabular}{ccc}
\hline Tes Awal & Perlakuan & Tes Akhir \\
\hline $\mathrm{O}_{1}$ & $\mathrm{X}$ & $\mathrm{O}_{2}$ \\
\hline (Sumber: & Adaptasi dari Sugiyono, 2016)
\end{tabular}

Keterangan:

$\mathrm{O}_{1}=$ Nilai pretest sebelum diberi perlakuan

$\mathrm{O}_{2}=$ Nilai posttest setelah diberi perlakuan

$\mathrm{X}=$ Pembelajaran Model Learning Cycle 5e

Teknik pengambilan sampel menggunakan cluster random sampling. Penelitian ini dilakukan di SMAN 1 Mataram. Sampel pada penelitian ini adalah kelas XI MIPA 5 dengan jumlah 30 peserta didik. Teknik pengumulan data berupa tes tertulis berbentuk soal pilihan ganda beralasan dilengkapi skala CRI. Instrumen tes hasil belajar sebelum digunakan harus memenuhi beberapa syarat yaitu uji validitas, reliabilitas, tingkat kesukaran dan daya beda. Uji analisis data menggunakan uji-t sampel berpasangan dengan taraf signifikan $5 \%$.

Tahap pertama penelitian dilakukan penulusuran miskonsepsi dengan memberikan pretest sebagai tahap identifikasi miskonsepsi. Setelah dilakukan identifikasi miskonsepsi, selanjutnya dilakukan remediasi terhadap miskonsepsi melalui pembelajaran dengan model learning cycle 5e. Pada akhir pembelajaran diberikan posttest kemudian data yang diperoleh ditabulasikan untuk dianalisis berkaitan dengan perubahan pemahaman konsep dan efektivitas model learning cycle $5 e$ dalam meremidiasi miskonsepsi.

\section{HASIL DAN PEMBAHASAN}

Penelitian ini bertujuan untuk mengetahui tingkat miskonsepsi peserta didik sebelum dan setelah remediasi serta mengetahui pengaruh model learning cycle 5e terhadap miskonsepsi. Sebelum menerapkan model pembelajaran learning cycle 5e diberikan pretest sebanyak 20 soal pilihan ganda beralasan dengan tujuan identifikasi miskonsepsi peserta didik. Adapun tingkat paham konsep miskonsepsi dan tidak paham konsep sebelum remediasi seperti pada Gambar 1.

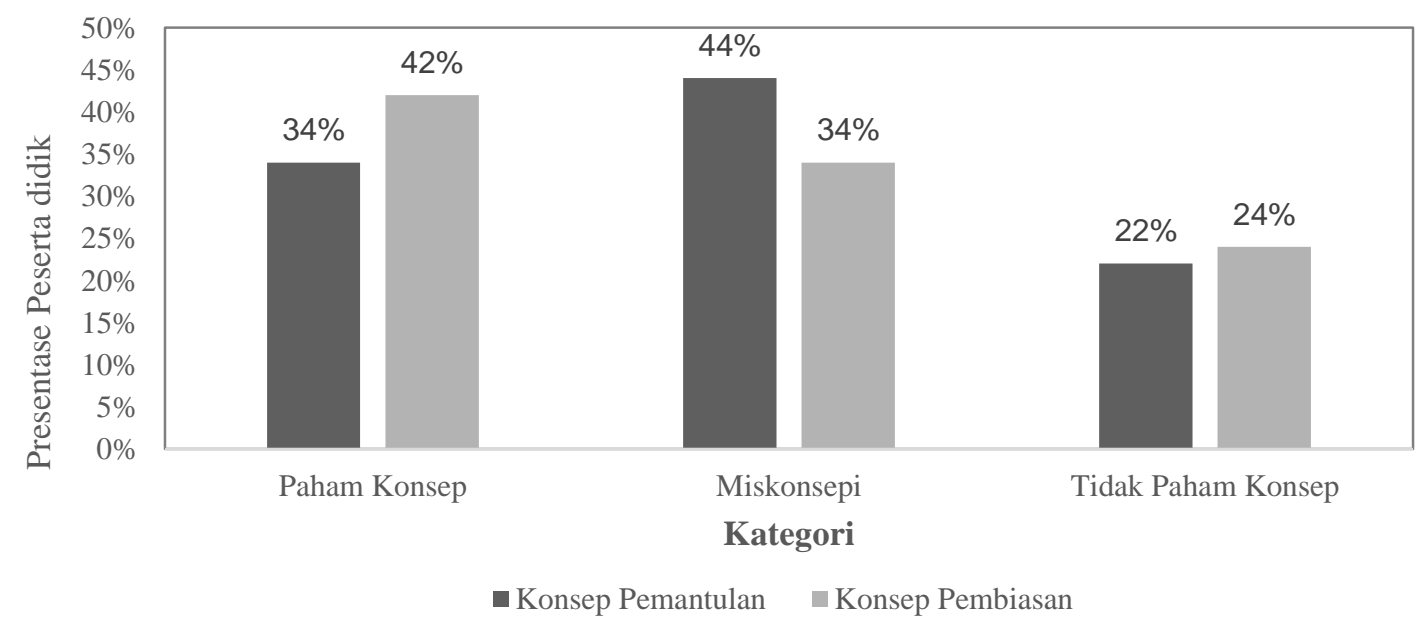

Gambar 1. Grafik Tingkat Paham Konsep Miskonsepsi dan Tidak Paham Konsep Sebelum Remediasi

Berdasarkan Gambar 1 diatas terlihat bahwa pada konsep pemantulan terdapat $34 \%$ peserta didik memahami konsep dengan baik, $44 \%$ peserta didik mengalami miskonsepsi, dan $22 \%$ peserta didik tidak paham konsep, sedangkan pada konsep pembiasan terdapat $42 \%$ peserta didik memahami konsep dengan baik, 34\% peserta didik mengalami miskonsepsi dan $24 \%$ peserta didik tidak paham konsep. 
Selanjutnya analisis miskonsepsi untuk masing-masing indikator soal dijelaskan pada Gambar 2.

Berdasarkan data yang diperoleh, pada konsep pemantulan miskonsepsi tingkat tinggi terjadi pada indikator 2 dan indikator 5 yaitu masing-masing sebesar $60 \%$. Indikator 2 yaitu tentang menganalisis permasalahan yang berkaitan dengan pemantulan cahaya, terdiri dari dua item soal yaitu tentang menentukan besar sudut pantul dari peristiwa pemantulan dan menentukan arah berkas sinar pada sistem optik yang mengalami dua kali pemantulan. Miskonsepsi tentang menentukan besar sudut pantul terjadi karena peserta didik beranggapan bahwa sudut $30^{\circ}$ merupakan sudut datangnya cahaya hal ini dapat dilihat dari tingginya indeks keyakinan peserta didik dalam menjawab soal tersebut, sedangkan konsep yang benar adalah sudut datangnya cahaya adalah terhadap garis normal yang berarti $60^{\circ}$. Miskonsepsi tentang menentukan arah berkas sinar pada sistem optik yang mengalami dua kali pemantulan dikarenakan sebagian besar peserta didik tidak dapat menggambarkan ilustrasi dari pertanyaan tersebut sehingga menjawab salah dan pada bagian alasan peserta didik tidak dapat menjelaskan alasan dalam menjawab akan tetapi peserta didik memiliki keyakinan yang tinggi akan jawaban yang diberikan benar.

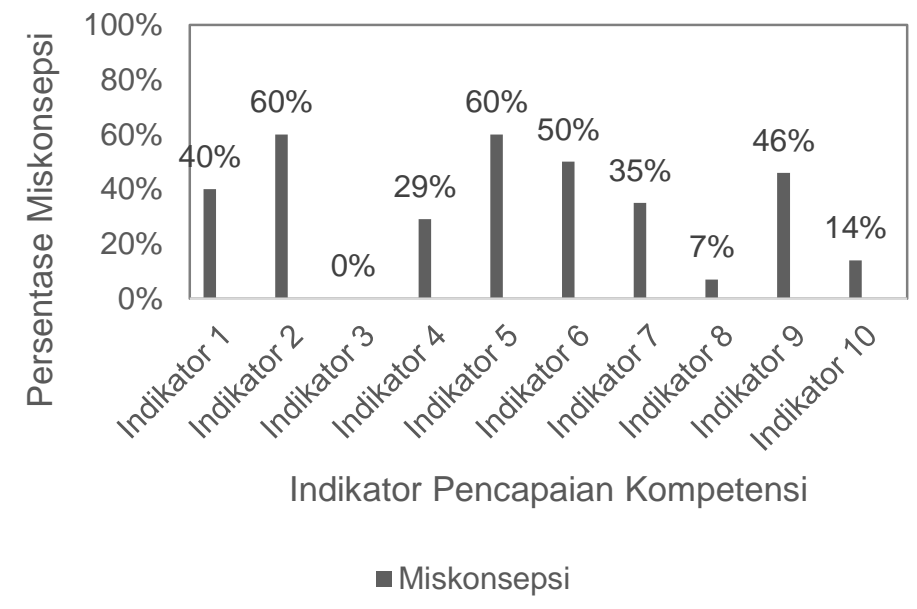

Gambar 2. Grafik tingkat miskonsepsi per indikator soal sebelum remediasi

Indikator 5 yaitu tentang menyimpulkan sifat bayangan yang menganalisis permasalahan yang berkaitan terbentuk dari hasil perhitungan dan soal dengan prinsip cermin lengkung terdiri dari tiga item soal. Soal yang pertama yaitu tentang menentukan sifat bayangan pada cermin cekung melalui perhitungan, terjadi miskonsepsi karena peserta didik tidak dapat menarik kesimpulan mengenai sifat-sifat bayangan yang terbentuk dari hasil perhitungan mencari jarak bayangan dan keyakinan yang tinggi dalam menjawab, soal yang kedua yaitu tentang menentukan pernyataan yang benar dari beberapa pernyataan yang disajikan miskonsepsi terjadi karena peserta didik salah dalam terakhir dari indikator 5 yaitu tentang menentukan jarak benda ke cermin cembung, terjadi miskonsepsi karena pilihan jawaban yang diberikan peserta didik salah beserta alasannya. Hal ini dikarenakan pada bagian alasan peserta didik salah dalam mengidentifikasi variabel-variabel yang diketahui seperti jarak fokus pada cermin cembung yang seharusnya bernilai negatif () dan bayangan maya yang seharusnya bertanda negatif (-), dengan tidak mengikuti aturan tersebut pilihan jawaban tetap ada pada option jawaban, hal inilah yang 
menyebabkan peserta didik memiliki keyakinan yang tinggi akan kebenaran jawaban yang diberikan.

Pada konsep pembiasan terjadi miskonsepsi pada tingkat sedang dan rendah. Miskonsepsi tingkat sedang tejadi pada indikator 6 , indikator 7 , dan indikator 9, sedangkan miskonsepsi tingkat rendah terjadi pada indikator 8 dan indikator 10 . Indikator 6 yaitu menjelaskan tentang konsep pembiasan cahaya terjadi miskonsepsi sebesar 50\%. Miskonsepsi terjadi disebabkan karena peserta didik keliru memahami konsep apakah air lebih memiliki medium yang lebih rapat daripada udara atau sebaliknya, alasan lain adalah peserta didik keliru dalam memahami atau menghapal bunyi dari hukum pembiasan tersebut sehingga setengah dari peserta didik menjawab sinar akan dibelokkan mendekati garis normal dan sangat yakin bahwa jawaban tersebut benar. Konsep yang benar adalah sinar akan dibelokkan menjauhi garis normal karena indeks bias air lebih besar daripada udara atau air memiliki medium yang lebih rapat daripada udara dan sesuai dengan Hukum Snelius II yaitu apabila sinar datang dari medium lebih rapat ke medium kurang rapat makan sinar akan dibiaskan menjauhi garis normal.

Indikator 7 yaitu menentukan konsep, prinsip, dan/hukum tentang pembiasan terjadi miskonsepsi sebesar 35\%. Indikator 7 terdiri dari dua item soal yaitu tentang menentukan persamaan Snellius dari gambar yang disajikan dan tentang syarat terjadinya pemantulan sempurna. Pada soal menentukan persamaan Snellius peserta didik keliru apakah persamaan yang digunakan adalah rumus sinus atau cosinus. Terjadi miskonsepsi karena indeks keyakinan tinggi walaupun menjawab salah. Miskonsepsi tentang syarat terjadinya pemantulan sempurna terjadi karena kesalahan peserta didik dalam menentukan syarat terjadinya pemantulan sempurna akan tetapi mempunyai keyakinan yang tinggi akan kebenaran jawaban yang diberikan.

Indikator 9 yaitu menjelaskan sifat pembiasan cahaya pada lensa terjadi miskonsepsi sebesar $46 \%$. Indikator 9 terdiri dari empat item soal yaitu tentang menentukan sifat pembiasan pada lensa cekung, lensa cembung, menentukan grafik hubungan antara jarak fokus dengan kekuatan lensa, dan menentukan ciri-ciri lensa cembung. Menentukan sifat pembiasan cahaya pada lensa cekung terjadi miskonsepsi karena peserta didik tersebut sangat yakin bahwa cahaya yang melewati sebuah lensa akan dipantulkan sehingga cahaya menyebar. Konsep yang benar adalah apabila terdapat seberkas cahaya yang melewati sebuah lensa, maka berkas cahaya tersebut akan dibiaskan. Menentukan sifat pembiasan pada lensa cembung yaitu menghidupkan sebuah senter dengan lensa cembung. Konsep yang benar dari pertanyaan ini adalah cahaya senter berpusat ada satu titik karena lensa cembung mempunyai sifat konvergen/mengumpulkan cahaya sehingga apabila ada sebuh cahaya melewati lensa cembung maka cahaya tersebut akan berpusat pada suatu titik. Sebagian besar peserta didik menjawab bahwa cahaya senter akan menyebar dengan alasan dalam pengamatan sehari-hari ketika menyalakan senter maka cahaya menyebar dan keyakinan yang tinggi menjadi indikator bahwa peserta didik telah mengalami miskonsepsi. Pada pertanyaan ini peserta didik tidak menghubungkan jawabannya dengan konsep pembiasan yang terjadi pada lensa cembung.

Setelah miskonsepsi berhasil diidentifikasi selanjutnya dilakukan remediasi melalui pembelajaran dengan model learning cycle 5e. Pada akhir pembelajaran, peserta didik diberikan posttest dengan soal yang berbeda dengan 
soal pretest namun masih dalam indikator soal yang sama.

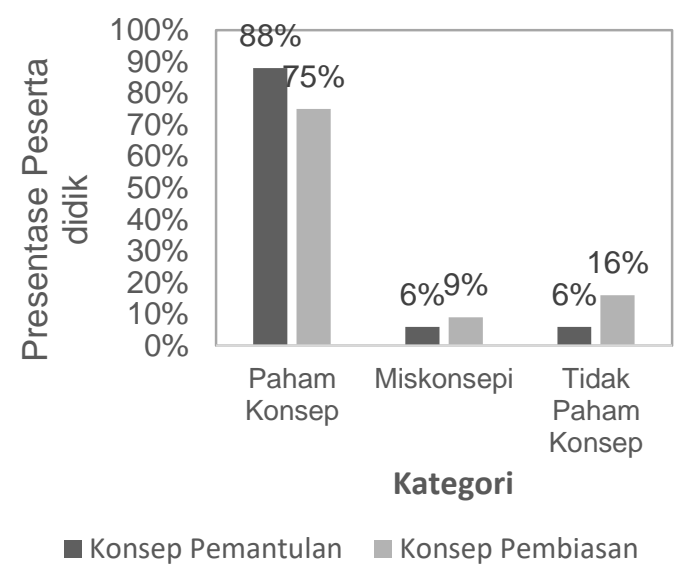

Gambar 3. Grafik Tingkat Paham Konsep, Miskonsepsi dan Tidak Paham Konsep Setelah Remediasi

Analisis miskonsepsi akhir peserta didik setelah diberikan perlakuan terlihat bahwa pada konsep pemantulan terdapat $88 \%$ peserta didik memahami konsep dengan baik, $6 \%$ peserta didik mengalami miskonsepsi, dan $6 \%$ peserta didik tidak paham konsep, sedangkan pada konsep pembiasan terdapat $75 \%$ peserta didik memahami konsep dengan baik, 9\% peserta didik mengalami miskonsepsi dan $16 \%$ peserta didik tidak paham konsep. Miskonsepsi awal pada konsep pemantulan sebesar $44 \%$ dan miskonsepsi akhir setelah dilakukan remediasi sebesar $6 \%$ sedangkan pada konsep pembiasan miskonsepsi awal sebesar $34 \%$ dan setelah dilakukan remediasi miskonsepsi akhir sebesar 9\%. Terlihat bahwa adanya penurunan tingkat miskonsepsi setelah dilakukan remediasi menggunakan model pembelajaran learning cycle 5e. Pada konsep pemantulan, penurunan miskonsepsi sebesar $38 \%$ dan pada konsep pembiasan penurunan miskonsepsi sebesar 25\%. Analisis miskonsepsi akhir masing-masing indikator soal dapat dilihat Grafik 4 berikut.

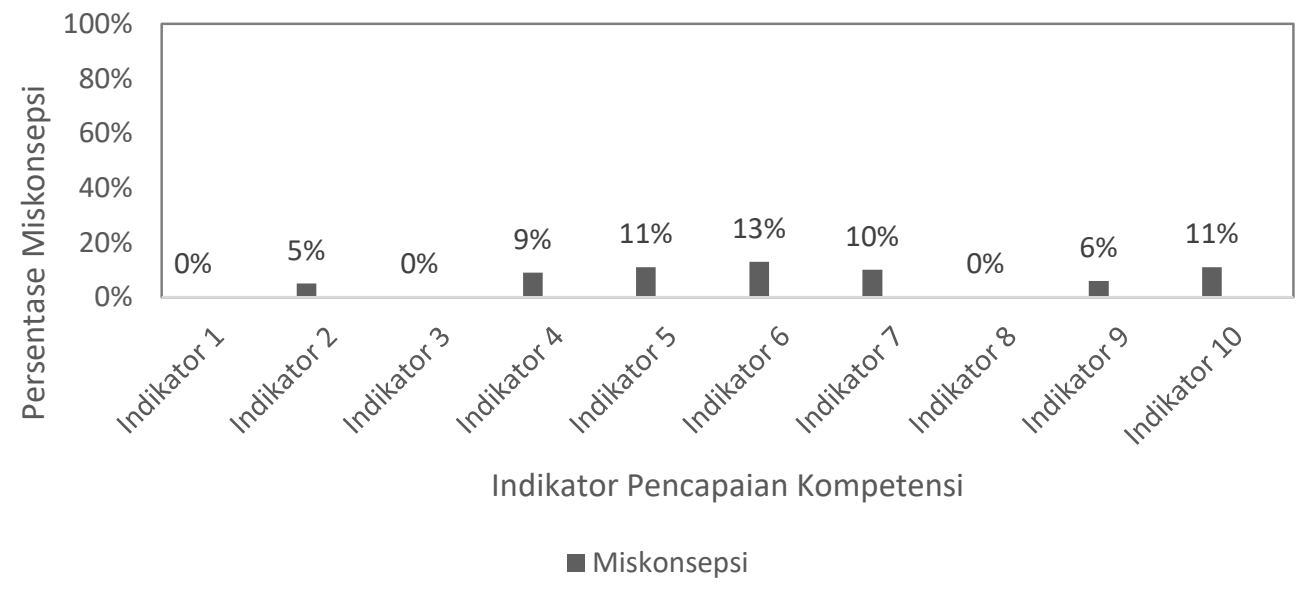

Gambar 4. Grafik Tingkat Miskonsepsi per Indikator Soal Setelah Remediasi

Hasil penelitian menunjukan bahwa sebelum dilakukan remediasi, peserta didik telah memiliki gagasan atau ide-ide tentang konsep yang dipelajari. Hal ini dapat dilihat dari profil miskonsepsi peserta didik yang cukup beragam pada pre-test menggunkan model CRI modifikasi. Proses perubahan miskonsepsi dapat terealisasikan pada tahapan-tahapan dalam model pembelajaran learning cycle $5 e$.

Fase engagement berperan penting dalam menarik perhatian peserta didik, dimana peserta didik diajak untuk terlibat langsung dalam pembelajaran melalui pemberian pertanyaan-pertanyaan. Pertanyaan yang diajukan bertujuan untuk 
menggali prakonsepsi yang dimiliki peserta didik.

Pada tahap exploration peserta didik secara berkelompok diberikan kesempatan untuk melakukan literasi dan diskusi kelompok untuk membuktikan sendiri apakah prakonsepsi yang dianggap benar sudah sesui dengan konsep para ilmuan. Pada tahap explanation peserta didik diberikan kesempatan untuk menjelaskan konsep dengan kalimat sendiri kemudian diberikan kesempatan untuk meluruskan miskonsepsi.

Tahap elaboration memberikan kesempatan untuk mengaplikasikan konsep yang telah didapatkan untuk memecahkan masalah-masalah dengan konteks yang berbeda-beda. Tahap evaluation bertujuan untuk mengevaluasi tahap pembelajaran mulai dari tahap pertama hingga akhir. Dalam tahap ini dilakukan observasi terhadap pengetahuan dan kecakapan peserta didik, sedangkan perserta didik mengevaluasi pekerjaannya sendiri dan peserta didik lain.

Berdasarkan hasil uji normalitas data tes awal dan akhir hasil belajar menunjukkan bahwa data terdistribusi normal. Selain itu dilakukan uji hipotesis untuk mengetahui adanya pengaruh model pembelajaran learning cycle $5 e$ terhadap miskonsepsi. Berdasarkan hasil perhitungan paired sample t-test diperoleh nilai $t_{\text {hitung }}$ lebih besar daripada $t_{\text {tabel }}$ yaitu $8,042>2,045$. Jadi dapat dinyatakan bahwa model pembelajaran learning cycle $5 e$ berpengaruh terhadap miskonsepsi.

Dalam kegiatan pembelajaran, pengajar sebaiknya membantu peserta didik untuk mengembangkan pemahamannya dengan memberikan: arahan dan organisasi untuk belajar, motivasi belajar, penjelasan konsep yang sulit dipelajari sendiri oleh peserta didik, kegiatan yang dapat membantu peserta didik mengenali (menyadari) dan memperbaiki miskonsepsi (Gunawan, 2015).

Hasil penelitian ini sesuai dengan penelitian yang dilakukan oleh Taufik (2012) bahwa implementasi model pembelajaran learning cycle $5 e$ mampu menurunkan proporsi mahasiswa yang mengalami miskonsepsi pada konsep gaya, yakni dari $46 \%$ menjadi 2,8\%, Taufiq (2012) membuktikan bahwa pembelajaran siklus belajar (learning cycle) 5e merupakan salah satu model pembelajaran yang efektif untuk meremediasi miskonsepsi fisika dan penelitian oleh Shofiyah (2016) membuktikan bahwa miskonsepsi pada konsep gerak dan gaya berhasil diremediasi sebesar $64 \%$ melalui pembelajaran dengan siklus belajar.

\section{PENUTUP}

Berdasarkan penelitian maka dapat disimpulkan bahwa tingkat miskonsepsi peserta didik pada materi optik geometris mengalami penurunan setelah diberikan remediasi. Hal ini menandakan bahwa terdapat pengaruh model pembelajaran learning cycle 5e terhadap miskonsepsi.

Oleh karena itu, penting sekali dilakukan tes miskonsepsi untuk konsep fisika yang lain agar dapat dilakukan remediasi. Selain itu, sebaiknya kegiatan mendiagnosis miskonsepsi dilengkapi dengan wawancara agar dapat menelusuri miskonsepsi siswa secara mendalam dan dapat mengetahui penyebab siswa mengalami miskonsepsi.

\section{REFERENSI}

Arikunto, S. 2014. Prosedur Penelitian, Suatu Pendidikan Praktik. Jakarta: Rineka Cipta.

Gunawan, G. (2015). Model Pembelajaran Sains berbasis ICT. Mataram: FKIP Unram 
Hakim, A., \& Kadarohman, A. (2012). Student Concept Understanding of Natural Products Chemistry in Primary and Secondary Metabolites Using the Data Collecting Technique of Modified CRI. International Online Journal of Educational Sciences, 4(3), 544 - 553.

Hasan,S., Bagayoko, D., \& Kelley, E. L. (1999). Misconception and the certainty of response index (CRI). Physics Education, 34, 294-299.

Hikmawati. 2015. Pembelajaran Fisika dengan Model Siklus Belajar 5e (Engage, Explore, Explain, Elaborate, Evaluate) Sebagai Upaya Meningkatkan Kecakapan Hidup Siswa. Jurnal Pendidikan Fisika dan Teknologi, (1)1, 24-37.

Irawan, E., Riyadi, R., \& Triyanto, T. 2012. Analisis miskonsepsi mahasiswa STKIP PGRI Pacitan pada mata kuliah pengantar dasar matematika pokok bahasan logika ditinjau dari gaya kognitif mahasiswa. Jurnal Penelitian Pendidikan,4(1), 643652.

Lestari, P. A. S., Rahayu, S., \& Hikmawati. 2015. Profil Miskonsepsi Siswa Kelas X SMKN 4 Mataram pada Materi Pokok Suhu, Kalo, dan Perpindahan Kalor. Jurnal Pendidikan Fisika dan Teknologi, 1(3).

Pebriyanti, D., Sahidu, H., \& Sutrio, S. (2015). Efektifitas Model Pembelajaran Perubahan Konseptual Untuk Mengatasi Miskonsepsi Fisika pada Siswa Kelas X Sman 1 Praya Barat Tahun Pelajaran 2012/2013. Jurnal Pendidikan Fisika dan Teknologi, 1(2), 92-96.

Shofiyah, N. 2016. Remediasi Miskonsepsi Konsep Gerak dan Gaya Melalui Penerapan Model Pembelajaran 7E (Learnig Cycle) pada Mahasiawa Calon Guru IPA Universitas Muhammadiyah Sidoarjo. Jurnal Sains dan Pendidikan Fisika, 12(1), 128-135.
Silung, S. N. W., Kusairi S., Zulaikah, S. 2016. Diagnosis Miskonsepsi Siswa di Kota Malang pada Konsep Suhu dan Kalor Menggunakan Three Tier Test. Jurnal Pendidikan Fisika dan Teknologi, (2) 3, 95-105.

Sugiyono. 2016. Metode Penelitian Pendidikan (Pendekatan Kuantitatif, Kuaitatif dan R\&D). Bandung: Alfabeta.

Suparno, P. 2005. Miskonsepsi dan Perubahan Konsep dalam Pendidikan Fisika. Jakarta: PT Grasindo.

Taufik, M., Hindarto,N., \& Khumaedi. 2010. Student's Science Misconceptions Concerning The State Changes of Water and Their Remediation Using Three Different Learning Models In Elementary School. Jurnal Pendidikan Fisika Indonesia, 7, (7479).

Taufiq, M. 2012. Remediasi miskonsepsi mahasiswa calon guru fisika pada konsep gaya melalui penerapan model siklus belajar (learning cycle) 5e. Jurnal Pendidikan IPA Indonesia, 1(2). 